\section{Interferencias de la dieta en la terapia de litio}

\author{
P. Castrogiovanni y F. Pieraccini
}

Universita' Degli Studi di Siena, Instituto de Clínica de las Enfermedades Nerviosas y Mentales, Cátedra de Psiquiatría, Pzza Duomo, 2, 53100 Siena, Italia

Se conocen variaciones en las concentraciones de litio en suero en pacientes tratados con carbonato de litio. Con frecuencia, estas variaciones se relacionan con algunas variables que sabemos que influyen en las concentraciones de litio en suero (variaciones de dosis, presencia de cloruro de sodio en la dieta, terapias concomitantes, etc.). Con respecto a esta cuestión, describimos un caso que indica un factor de variabilidad que, aunque se haya considerado ya, puede ser subestimado en la práctica clínica.

GP es una mujer casada de 56 años sin enfermedades somáticas con una prolongada historia de trastorno bipolar I (predominantemente maniaco, sin rasgos psicóticos) tratada con medicaciones antipsicóticas sin beneficios suficientes. Desde nuestro primer contacto ha estado tomando sólo carbonato de litio (300 mg, tid) con remisión de sus síntomas y mantenimiento del equilibrio. Durante un periodo de ocho años, las concentraciones de litio en suero de la paciente han estado en un rango entre 0,50 y 0,60 meq/L. La obediencia de la paciente ha sido siempre buena y ha aumentado también por la presencia de cierto grado de comprensión de la enfermedad y un estrecho control de sus familiares.
Después, uno de los seguimientos reveló una fuerte reducción del nivel de litio (valores de 0,10 meq/L) sin ningún cambio en la dosis de carbonato de litio. Un nuevo examen de laboratorio confirmó el mismo resultado. Otro seguimiento reveló que la paciente solía beber agua en la que añadía una tableta efervescente, un producto muy conocido en el mercado italiano que viene en envase manejable y proporciona un "agua efervescente y digestiva para las comidas". Cada paquete contiene $10 \mathrm{~g}$ de bicarbonato de sodio al que se añaden ácido málico y tartárico en cantidades que no se conocen con exactitud. Sugerimos a la paciente que interrumpiera el uso de esta bebida y se sometiera de nuevo al examen de laboratorio. La dosis siguiente de concentración de litio mostró valores de 0,40/0,50 meq/L. Una nueva disminución repentina de los valores de litio a $0,20 \mathrm{meq} / \mathrm{L}$ confirmada en una prueba doble de laboratorio siguió a la reanudación del consumo.

Obviamente, este producto, como otros agentes alcalinizantes, si se utiliza con frecuencia y en grandes cantidades, puede disminuir el nivel de litio en suero. Debido a la popularidad del uso de este producto y de otros que contienen cantidades elevadas de sales, proponemos dirigir nuestra atención a su posible interferencia de la terapia de litio. La cuestión es particularmente importante en especial para los pacientes que están acostumbrados a tomar esta clase de producto y que no hacen un seguimiento regular de las concentraciones de litio. Por esta razón, podría haber un riesgo de disminución en los niveles de medicamento en sangre con recaída posterior o el comienzo de los síntomas de supresión siguientes, no explicable de otro modo. 